\title{
Counting Blessing: The Effect of Gratitude Training on Prosocialness among Teachers in Inclusive School
}

\author{
Ika Febrian Kristiana \\ Faculty of Psychology, Diponegoro \\ University, Semarang, Indonesia \\ Ika.f.kristiana@gmail.com,
}

\author{
Erin Ratna Kustanti \\ Faculty of Psychology, Diponegoro \\ University, Semarang, Indonesia \\ erintanjung@yahoo.co.id,
}

\author{
Salma \\ Faculty of Psychology, Diponegoro \\ University, Semarang, Indonesia \\ salmaibrahim1707@gmail.com
}

\begin{abstract}
Gratitude can motivate everyone to be pro-socially behaved, create a positive social relation, and build the sense of togetherness in the school community. This research examines to measure the effect of gratitude training on teacher's prosocial behavior in inclusive school with special need student (SEN). This is the quasi experimental research. There were 120 subjects divided into two groups, control and experiment. The treatment given to the experiment group was gratitude training. Data collected by using the sixteen items of the prosocialness scale for adults by Caprara et. al (2005) that has an excellent reliability $(\omega=0.980,95 \% \mathrm{Cl}=0.972,0988)$ and distributed twice on pre and post-test. Statistical analysis showed $\left(r_{B}=0.339, p=.001\right.$, Hodges' $g=-3.000,95 \% \mathrm{Cl}=-5.00,-1.00$ ) that is means gratitude training have had an effect that tends to be moderate to the teacher's prosocialness. However, this research's findings showedthat gratitude is one of important psychological strength to motivate teachers' prosocialness in inclusive school. This finding can serve as recommendations for prosocialness improvement programs for inclusive teachers in Indonesia with all its realities.
\end{abstract}

Keywords: gratitude, prosocial, teacher, inclusive school, SEN

Received 26 April 2020/Accepted 8 June 2021 @Author all rights reserved

\section{Introduction}

Inclusive education in Indonesia has been established since 2009, but the attention to the implementation itself is still considered a lack. This condition was illustrated in a research by Kaplan, Lewis, \& Mumba (2007) which portrayed the inclusive education in three countries, namely England, Zambia and Indonesia. In his research, Kaplan et.al (2007) explained that the execution in Indonesia was still far from appropriate in terms of infrastructure, e.g. the school building's condition and its sanitation, the lack of participation from teachers and school's administration staff in informing the learning process and their inclusive attitude towards the students which built the students' negative perception. This implementation was also recorded by Sunardi, Yusuf, Gunarhadi, Priyono, 
\& Yeager (20II) by involving I 86 inclusive schools which described that, in terms of school management, there were $19 \%$ inclusive schools which did not apply the appropriate student selection process without any record on how the teachers or other academic staffs performed in those inclusive schools.

A teacher plays a crucial role in the inclusive education. A research on teachers' performance in England conducted by Robinson (2017) claimed that teachers participating in the government's "on the job training" showed a crisis in teaching efficacy. Other previous success of providing researches such as Forlin (2010) criticized the inclusive teachers' performance highlighting the teachers' lack of preparation which was proven to be the obstacles in applying the inclusive education. This problem became urgent since preparing the teachers to become effective educators in an inclusive school was not an instant process (Blanton \& Pugach, 2007). Internationally speaking, numerous criticisms regarding teachers' performances in an inclusive school were addressed to: I) the teacher's knowledge and skills preparation in which the trainings provided were proven to be insufficient in improving their knowledge and skills (Hodkinson, 2005;jones, 2006); 2) the attitude and psychological condition of the teachers who taught students with special needs in which, in this case, by having the positive attitude and good psychological condition, they would have been able to improve their teaching and overcome any possible obstacles (Slee, 200I; Lambe \& Bones, 2006).

A teacher's positive psychological and social condition such as, patience, compassion and strong desire to assist students with special needs is predicted to be influential in the best education for those exceptional children (Safran \& Safran, 200I). Other supporting studies claimed that when a teacher is in a good emotional state, he/she will be able to provide the necessary emotional support to students (Brown, Jones, LaRusso, \& Aber, 20I0; Tom, 2012), which will affect the students' adaptation process (Buyse,Verschueren, Verachtert, \& Van Damme, 2009; Maldonado-Carreño \& Votruba-Drzal, 20II). Several researches pointed out the importance of focusing on the teacher's psychological and social condition, especially not only those who teach the students with special needs but also including those who worked in an inclusive school due to the considerable challenge in teaching these children which demanded patience, tolerance and empathy, acceptance and other 
positive attitudes including having a willingness to help students achieve learning goals and develop their potential (Robertson, Chamberlain, \& Kasari, 2003; Yell, Katsiyannis, Drasgow, \& Herbst, 2003). Social psychological demands as mentioned earlier are attached to the role of a teacher. In performing their job duties, teachers often have to be capableto help, care for, or entertain students. A series of voluntary actions to help is a definition of prosocialness (Bar-Tal, 1982; Batson\& Shaw, 1991; Schroeder, Penner, Dovidio, \& Piliavin, 1995).

Prosocial behavior in adult individuals can be done to obtain certain interests, social meaning, and heuristic values. In adulthood, a person's tendency to act prosocial may receive threats or obstacles from interpersonal experiences (such as experiences in the work environment) that change a person's intention or goal to help, for example, personal competition, achievement, and individual strengths. Beside depends on the capacity of adults themselves to assist, support others, and actively build or maintain strong social relationships (Eisenberg et. al., 2002). Teachers in inclusive schools with a description of the work context and tasks that must be done are an example of an identical adult's job role with high demands in showing prosocial behavior.

The process of prosocial sense making has been studied to have a positive impact on the formation of organizational commitment. Teachers who have a prosocial sense will interpret personal actions and identities as caring for the organization (school). An indicator of a teacher having good affective commitment is a prosocial sense of the school where he works (Grant, Dutton, \& Rosso, 2008). This also indicates that teachers have an attachment to the school where they work (Grant, Dutton, \& Rosso, 2008). Prosocial behavior is also synonymous with extra-role behavior as a description of organizational citizenship behavior (Robbins, 2002).Teachers who have prosocial behavior will be willing to volunteer to do work with full of commitment and even do tasks outside the minimum responsibility assigned to them and not easily pass the responsibility on to colleagues. Furthermore, prosocialness will make teachers have satisfaction with their work (Aydin \& Aslan, 2021). 
Teachers should be able to be role models of prosocial behavior for students and the surrounding community. For this reason, teachers need to have and develop high interpersonal sensitivity and a caring attitude to respond effectively to problems that arise both in the school environment and in the community.

Previous research reports that one of the factors that is quite consistent in influencing the formation of prosocialness is gratitude (e.g Tsang, 2006Bartlett \& DeSteno, 2006; McCullough, Emmons, \& Tsang, 2002). Some theorists believe that gratitude is a function of nurturing social relations through mutual encouragement, prosocial behavior between benefactor and recipient (Algoe \& Haidt, 2004; Emmons \& McCullough, 2004).

The potential positive effects of gratitude in individuals and society are numerous, and researchers are only beginning to explore them. Gratitude also shows an important impact at workplace. Andersson, Giacalone, \& Jurkiewicz's (2007) research shows that employees associated feelings of gratitude with a greater sense of social responsibility towards coworkers and social issues. Early research on gratitude focused primarily on the role of gratitude in social exchange. For example, Trivers (197I) theorizes that gratitude evolves to increase the odds prosocial behavior will be reciprocated, thus perpetuating reciprocal altruism and its health-related benefits. McCullough and colleagues theorize that gratitude serve as moral or prosocial barometer that a philanthropist deliberately giving benefits or assistance to other people (beneficiaries) then beneficiaries will be motivated to acting up prosocial back to generous (McCullough et.al, 200 I; McCullough et al., 2006). Research has supported that individual more likely to evoke experience gratitude in return (Lane \& Anderson, 1976; Tesser, Gatewood, \& Driver, 1968). So, gratitude maybe advance and maintain an economic motive in exchange for action prosocial (Tsang \& Martin, 2019).

Gratitude is gratitude addressed to other people that is raised through social exchanges between the person being assisted and the person who provides assistance (generous) (Blau, 1964). Research has shown that gratitude has positive effects not only for the person being helped but also for the helpers themselves. Expressions of gratitude seem to function as a moral booster in enhancing prosocial behavior (McCullough et al., 200I). A study has shown that when assistance from helpers is appreciated by beneficiaries then helpers are 
more willing to help these beneficiaries again (Clark, Northrop, \& Barkshire, 1988; Rind \& Bordia, 1995) and to help others (Clark, Oullette, Powell, \& Milberg, 1987; Goldman, Seever, \& Seever, 1982).

An individual with a high sense of gratitude is associated as the person who can easily grasp and comprehend the positive value of every event and channel it to others (Emmons \& McCullough, 2003). In particular, gratitude is considered to be positively related to optimism and hope, disallow negative feelings such as depression and anxiety, and aiming to support social relation. Moreover, gratitude can increase a person's success in life (Emmons et. al., 2003). Researches on gratitude in an education institution atmosphere revealed that gratitude can motivate everyone to be pro-socially behaved, create a positive social relation, and build the sense of togetherness in the school community (Chan, 20I3). This research's hypothesis is that gratitude training has a positive effect to teachers' prosocialness in inclusive schools.

Unfortunately, studies concerning on a teacher's prosocialness in the context inclusive education, particularly experimental studies by applying psychological interventions, have never been conducted (e.g Majoko, 2019; Brown, 2019) which described teacher's prosocialness was part of the competencies that need to be developed and taught to students in inclusive schools. This research applied experimental design which attempts to scrutinize the effectivity of the intervention based on the psychological empowerment provided to those who teach students with special needs through the gratitude training. Gratitude has been shown to predict more prosocial behavior (McCullough, Kilpatrick, Emmons, \& Larson, 200I).

\section{Method}

\section{Participant and Procedures}

This study applied the quasi experimental method. Recruitment of participants is carried out openly by determining certain criteria based on theoretical considerations, for example, by considering the gender-balanced proportion of participants in the treatment group and the control group. The number of participants was determined a priori by considering the type of statistical test to be used (Wilcoxon with matched sample), the 
statistical power, effect size, and measurement error. Using the G-power statistical program by inputing/choosing some criteria such as: one-tail hypothesis model, normal distribution, probability error $(\alpha=0.05)$, effect size $(d=0.3)$; and statistical power ( $I$ $\beta=0.95$ ), the estimated minimum total sample size is 47 each group or a total of 94 participants from both groups. Through a selection process based on criteria (educational background, age, type of disability of the students, and grade level), I 20 teacher from at least 7 public junior high school in Semarang and its surroundings. All participants also confirmed that they had never attended previous training based on psychological strength. They also signed informed consent as a form of willingness to be involved as research participants. In the informed consent, there was a brief description of the research, the rights and consequences of being a participant, and the confidentiality of participants' identity.

At first, participants were randomly assigned to one of two conditions. In the identity threat condition/experimental group $(\mathrm{N}=60)$, participants were given a gratitude training 2 times for 2 months; in the control condition $(\mathrm{N}=60)$, participants were not provided with the training at all. To perform a manipulation check, we required participants to fill out a prosocialness scale. Participants were presented with a detailed information letter and were informed that our study aimed to investigate the interplay between gratitude and prosocialness. Measurement was conducted twice by providing subjects with pre-test and post-test using the The sixteen items of the prosocialness scale for adults by Caprara,Steca, Zelli, \& Capanna (2005). This is a Likert type scale with five response options, namely never/ almost never correct (coded I), sometimes true (coded 2), sometimes true (coded 3 ), often correct (coded as 4 ), and almost always/ always true (coded 5). Reliability test shows $(\omega=0.980,95 \% \mathrm{Cl}=0.972,0.988)$, it can be said that the scale has an excellent reliability. Some examples of statements in Caprara's (2005) prosocialness scale (the first 6 statements) include: I am pleased to help my friends/colleagues in their activities, I share the things that I have with my friends, I try to help others, I am available for volunteer activities to help those who are in need, I am emphatic with those who are in need, and I help immediately those who are in need. The control in the experiment was done by matching subjects to demographic characteristic. The teachers' demographic data can be seen from this table. 
Table I

Teachers' Demographic Data

\begin{tabular}{lcc}
\multicolumn{1}{c}{ Data } & \multicolumn{2}{c}{ Group } \\
\cline { 2 - 3 } & $\begin{array}{c}\text { threat } \\
\text { condition }\end{array}$ & control condition \\
\hline Sex: & 28 & 28 \\
male & 32 & 32 \\
female & 41.61 & 41.34 \\
M age & 5.029 & 4.913 \\
SD age & $32-52$ & $33-51$ \\
Age range & & \\
Education background : & 0 & 0 \\
Bachelor in special education & 60 & 60 \\
Others & 3.2 & 3.17 \\
M SEN with physical disability at the class & & \\
&
\end{tabular}

Note: SEN (special educational needs); M (Mean); SD (Standard Deviation)

\section{Condition}

The distance between one training and the next training is 3 weeks. Both the experimental group and the control group each measured 2 times, the initial measurement and the final measurement. Initial measurements were considered as baseline data or pretest for the experimental group. The baseline prosocialness data are as follows: group with treat conditions $(M=50.817, S D=4.180)$ and control group $(M=49.883, S D=3.608)$.

After the initial measurement was carried out, treatment in the form of gratitude training was given to the experimental group (group with treatment conditions). Each meeting was given four gratitude training sessions, include: gratitude appraisal, gratitude recounting, gratitude reflection, and expression of gratitude. The detailed description and purpose of each gratitude training session is as follows:

Session I: Gratitude reappraisal

In this session, subjects were asked to identify the negative responses based on their past experience. Then, they were trained to change their perspectives towards their negative experiences by searching the silver lining of every event to produce the sense of gratitude. 
Session 2: Gratitude recounting

In this session, subjects were trained to express their happiness according to their own subjectivity by sharing things that they were fully grateful of. This aims to measure their tendency in expressing their gratitude and understand the importance of feeling gratitude.

\section{Session 3: Gratitude reflection}

This session asked the subjects to open their eyes to all the good things that had happened to them after coping with the obstacles preventing them to feel grateful. The training provided a state of self-reflection by observing other misfortune people around them.

\section{Session 4: Expression of Gratitude}

In this session, the subjects were asked to practice expressing their gratitude by all means necessary. This was considered effective enough to improve their emotional welfare.

The final condition was considered a posttest for the experimental group. After the entire treatment session was given to the experimental group, the final measurements were taken. Both the experimental and control groups were measured at the same time and place. The analysis of the hypothesis was carried out by comparing the final measurements of the two groups.

\section{Result}

To test the validity of the identity threat manipulation, a type of $t$-test for independent groups was conducted. Mann Whitney independent sample t-test was conducted with the prosocialness score as a variable and treat and/ or no treat as grouping variable. Prosocialness score was slightly higher in the threatening condition ( $M=53.767, S D$ =3.027) than in the non-threatening condition $(M=50.583, S D=5.649), W(I \mid 90)=-0.339$ (rank biserial correlation $/ \mathrm{r}_{\mathrm{B}}$ ), $p=.00 \mathrm{I}$, Hodges' $g=-3.000,95 \% \mathrm{Cl}=[-5.00,-1.00]$. In support of the gratitude training has an effect even though it is relatively small $\left(r_{B}=-0.339\right)$ to show prosocial behavior (prosocialness). Thus, the research hypothesis that there is an effect of gratitude training on the prosocialness of teachers in inclusion schools can be accepted. 


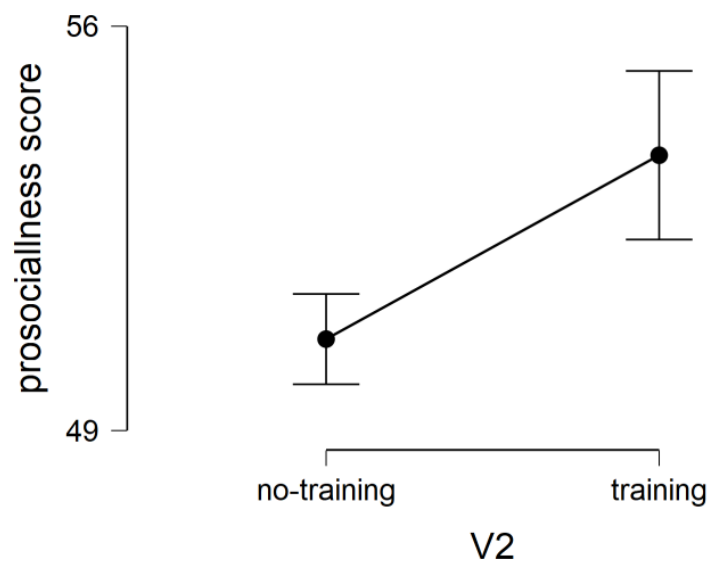

Figure I.Descriptive Plots of Prosocialness score

Figure $I$ is a plots diagram showing the mean difference in teachers' prosocialness scores from the time of the final measurement, in the treatment condition group and the control group. The treat condition group showed higher mean prosocialness scores after gratitude training. The following table provides more detailed information on the results of the descriptive analysis and different tests of the two measurements (initial and final) in the two groups of participants (with treat conditions and control conditions).

Table 2

Wilcoxon paired sample t-test of Prosocialness score in Experiment and Control Group

\begin{tabular}{lcccccccc}
\hline & M pre & M post & SD & SD post & W & P & $r_{B}$ & $95 \% \mathrm{Cl}$ \\
& \multicolumn{7}{c}{ pre } \\
experiment & 50.817 & 53.767 & 4.180 & 5.649 & 1246.500 & $* * *$ & 0.508 & $0.256,0.696$ \\
control & 49.883 & 50.583 & 3.608 & 3.027 & 450 & 0.066 & $0.35 \mathrm{I}$ & $-3.400 \mathrm{e}-5$, \\
& & & & & & & & 3.000
\end{tabular}

Note: pre (pre-test); post (post-test); W (Wilcoxon value); $\mathrm{p}$ (signicant value) $* * *=<0.0 \mathrm{I}$; $\mathrm{r}_{\mathrm{B}}$ (rank-biserial correlation coefficient); $\mathrm{Cl}$ (convident interval) 


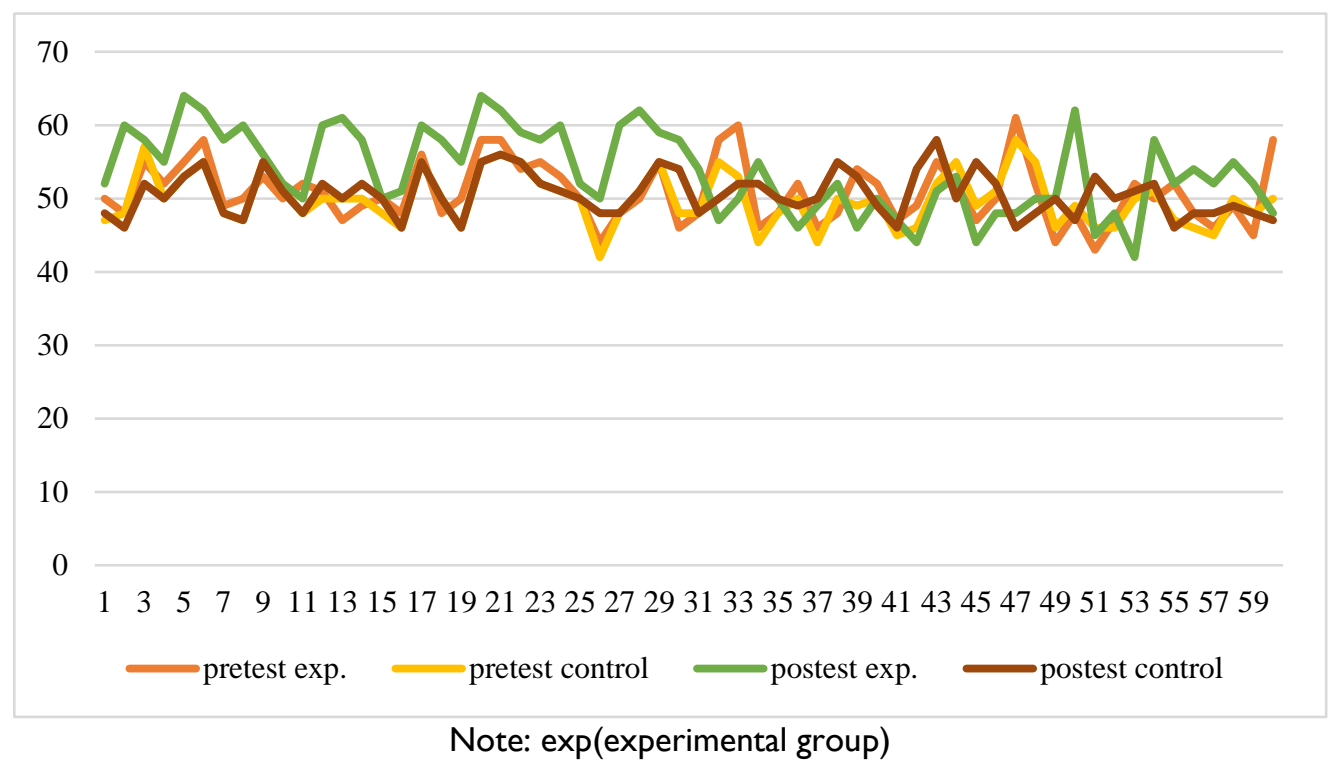

Note: $\exp (\operatorname{experimental}$ group)

Figure 2. Prosocialness scores of participants in the control and experimental groups

The prosocialness scores of each participant in the control and experimental groups in the pre-test and post-test measurements are shown in the graph above. It can be seen that the scores on the initial measurement in the control and experimental groups were relatively the same. Thus, control through matching and randomization can be said to be successful. Looking at the post-test scores of the experimental group (green line), it appears that more than $90 \%$ of the total participants showed a higher score than their pre-test scores (orange line). However, this was not the case in the control group. Post-test scores in the control group (yellow line) show similarity to their pre-test scores (brown line).

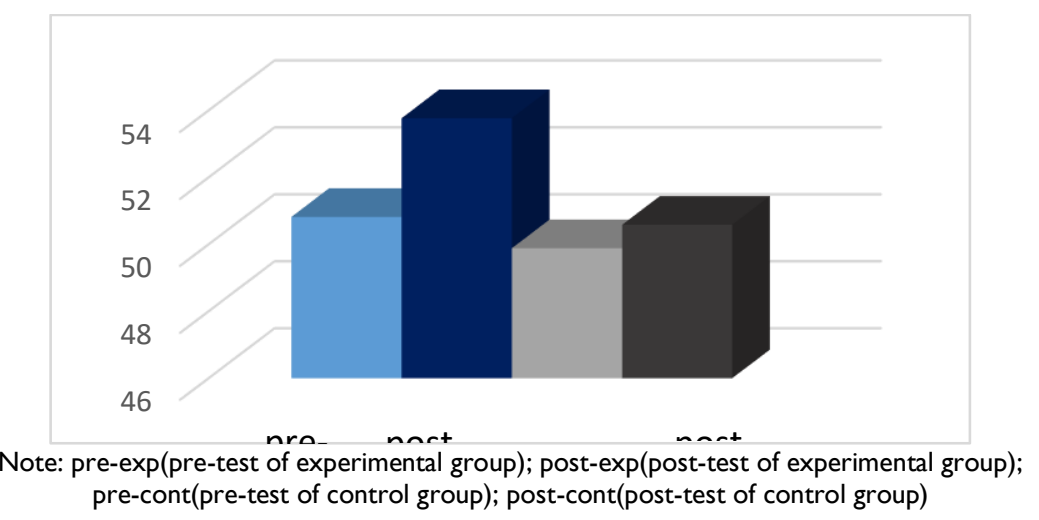

Figure 3. The Pre-test and Post-test Mean Scores of The Experimental and Control groups 
Looking more accurately, the bar chart in Figure 3 shows the difference in mean prosocialness scores in the two groups (control and experiment) from the initial measurement (pre-test) and the final measurement (post-test).

\section{Discussion}

Gratitude training is, basically, a strength-based intervention relying on a person's increasing positive potential by being grateful for every life event. This can not only be expressed through spoken language, but also in some stages which must be gone through so that an individual is able to express his/her real gratitude consciously in their behavior.

This study verifies findings from previous studies which report that gratitude motivates prosocial behavior (Bartlett and DeSteno 2006; Tsang 2006; Tsang et.al, 2019). Previous experimental studies also reported an effect of gratitude on prosocial behavior although the effect found was not large (Tsang et.al, 2019). Considering the previous literature, generally, gratitude can be interpreted as a positive emotional reaction to benefits received as goodwill of others (beneficiaries). Gratitude experiences with positive emotions will make individuals feel positive about benefits and generosity.Therefore, one of the possible consequences of gratitude is prosocial behaviour towards one's benefactor (McCullough et al., 200I; McCullough, Tsang,\& Emmons, 2004). Using the Broaden Built theory framework, positive emotions experienced by individuals can be a resource that will strengthen the emergence of these positive emotions or other positive emotions. For example, when someone is satisfied to receive benefits from others will encourage feelings of gratitude (Fredrickson, 2004). Furthermore, this gratitude will be strengthened and generate a sense of empathy and compassion so that it is motivated to help others, at least repay the kindness of those who have helped them.

Showing prosocial behavior seems to be part of a teacher's role. The demands for high prosocial behavior are higher for teachers who teach and assist students with special needs. Gratitude training motivates prosocial behavior in teachers since gratitude along with its manifestation applied by a teacher who teaches students with special needs will not only affect the students but it will also provide some sort of emotional control and 
prioritizing the positive emotion within (Howells, 20I2). That emotional states can mediate helpful behavior is not a new idea. Many previous studies have documented that a positive mood can enhance prosocial responses (e.g, Carlson, Charlin, \& Miller, 1988; Isen \& Levin, 1972). However, this effect is known to be limited by the hedonic limitation that only applies as long as the assistance requested is inexpensive for the helper as described by the Moral Affect Theory. The relationship between gratitude and prosociality is also explained by the Moral Affect Theory of McCullough et al. (200I). This theory defines gratitude as a moral emotion with three essential functions. As a moral barometer, gratitude indicates to the recipient that a philanthropist has given him a gift. As a moral motive, gratitude encourages prosocial behavior in beneficiaries both directly to benefactors and people. Finally, as a moral reinforcer, gratitude increases the likelihood that the benefactor will act prosocially to the recipient in the future. In line with the Moral Influence Theory on gratitude (McCullough et al. 200I), prosocial behavior is a response to gratitude. Gratitude can influence individuals to return favors through prosocial behavior (Bartlett and DeSteno 2006; Tsang 2006). Bartlett and DeSteno (2006) found that individuals who receive help from others experience gratitude and are more likely to show prosocial behavior to benefactors or other people. A reciprocal picture of the benefits obtained from others, namely by doing good or giving benefits to that person and being extended to others (Tsang et.al, 2019).

The emphasis of the goal of gratitude is to encourage one's prosocial actions, even if these actions are detrimental to oneself at this time. Meanwhile, gratitude and prosocialness research involving teachers as participants is still very rare. This is the aim of this research that gratitude will have a major effect in increasing the social behavior of teachers in inclusive schools without certain hedonistic boundaries. This emphasis is important given the context of inclusive education in Indonesia.

The national implementation of inclusive education in Indonesia is by transforming public schools into inclusive schools (Minister of National Education Regulation, 2009). This means that the school, which was originally a regular school by only providing educational services for normal students, must gradually provide educational services for students with special needs to study together under one roof with normal students. This reality makes 
regular school teachers have to adapt to new demands, namely to become inclusive teachers. It is not easy to teach and assist students with special needs to learn with normal students in class. Teachers who are accustomed to accompanying students to learn independently and quickly, with students with special needs certainly require teachers to provide assistance even individually to students during the learning process. In such situations, the teacher may not receive previous assistance; instead the teacher must provide assistance without hedonic restrictions. Therefore, the concept of gratitude which is emphasized is more personal awareness, not awareness of social norms.

The concept of gratitude which is personal awareness, for example, is gratitude which is based on the value of religiosity. There are several studies proving that spiritual and religious people tend to be more grateful. Individual those who experience the properties of religion, for example, their prayers are answered and lor experienced a miracle from God, were also more likely to report feelings of gratitude (Adler \& Fagley 2005; Lambert, Fincham, Braithwaite, Graham, \& Beach, 2009; Sandage, Hill, \& Vaubel, 20II; Tsang, Schulwitz, \& Carlisle, 2012). As it is well known that several world religions teach about the importance of gratitude (Emmons \& Crumpler, 2000). It then follows that one possible consequence of gratitude is prosocial behavior toward one's benefactor (McCullough et al., 2001; McCullough \& Tsang, 2004). As a religious country, of course, it is grateful to be part of the characteristics of the Indonesian population. Thus, strengthening the characteristics of gratitude will influence the intention to increase prosocial behavior. It can be understood that the teacher's gratitude for whatever has been accepted and given by God morally religiosity must be rewarded by doing good and helping students regardless of the conditions. For example, if the teacher is grateful for the physical and spiritual health favors given by God, the teacher will repay the blessings given by God by helping students who are not perfect physically and mentally. Therefore, the findings of this study prove that strengthening the experience of gratitude for teachers has a great effect on their prosocialness.

This study had some limitations that should be noted. Firstly, all data were based on teachers' self-reports, which could lead to common method variance issues. The use of multiple methods of assessment would be beneficial in future research. Secondly, This 
research limits the types of disabilities of students to physical disabilities. Even though this is a form of control in this experimental study, the results will be richer if there are several groups of teacher as participants in the experiment teach students with different types of disabilities. Mostly research about gratitude used scenarios as well as did in this study. Gratitude study that uses scenarios has potential limitations. First, gratitude studies using scenarios have the potential for low psychological realism (Hegtvedt, 1990). Second, participants reading a gratitude scenario may have difficulty experiencing the emotion of gratitude. This is what likely makes this grateful training have a low effect on individual prosociality. However, the results of this study still support previous studies that reported the effect of gratitude on prosocial behavior (eg Bartlett \& DeSteno, 2006; Grant \& Gino, 2010; Tsang et.al, 2019). However, a study conducted by Tsang et.al (2019) found that there were variations in the size of the help received with the emotions of gratitude shown by the participants. Even though a small favor is enough to encourage reciprocal behavior, it may not be big enough to generate an emotion of gratitude. In one of the gratitude training sessions, participants are invited to imagine the precious things they have received. This valuable thing seems to need to clarify its size or operation so that it will probably have a large difference in effect.

\section{Conclusion}

Based on the findings, it can be concluded through 4 sessions in the training of gratitude training has an effect in increasing the prosocialness of teachers in inclusive schools. Inclusive school teachers got benefit from the existence of gratitude training which can encourage them to do more prosocial behavior. Teachers' prosocial behavior has become the job demand characteristics of teachers, especially who teach students with special needs in their classes. Furthermore, teachers' prosocial behavior (including helping, empathy, loving, and being responsible for social problems in the workplace) becomes an asset in helping students learn, including students with special needs. This program can be recommended for all teachers who teach students with special needs, considering the realities of the implementation of inclusive education in Indonesia, to help teachers to increasing their psychological and social strength. 


\section{Acknowledgement}

The author would like to thank the Institute for Research and Community Service (LPPM) Diponegoro University Semarang, Indonesia for funding this research. The author also sends thanks to all junior high school teachers in Semarang and several surrounding cities that have been willing to participate in this research.

\section{References}

Adler, M. G., \& Fagley, N. S. (2005). Appreciation: Individual differences in finding value and meaning as a unique predictor of subjective well-being. Journal of personality, 73(I), 79-I I4. DOI: https://doi.org/ I0. I I I /j. I 467-6494.2004.00305.x

Andersson, L. M., Giacalone, R. A., \& Jurkiewicz, C. L. (2007). On the relationship of hope and gratitude to corporate social responsibility. Journal of Business Ethics, 70(4), 40I409. DOI: 10.1007/s 1055I-006-9| I8-I.

Algoe, S., \& Haidt, J. (2004). Witnessing excellence in action: The "other-praising" emotions of elevation, gratitude, and admiration. Unpublished manuscript, University of Virginia, Charlottesville.

Aydin, Z. A, \& Aslan, M., G. (202I). Psychological capital and job satisfaction in publicschool teachers: the mediating role of prosocial behaviours. Journal of Education for Teaching, 47(2), I47-I62. DOI: https://doi.org//0.1080/02607476.2021.1877086

Bar-Tal, D. (1982). Sequential development of helping behavior: A cognitive-learning approach. Developmental Review, 2(2), I0I-124.

Bartlett, M. Y., \& DeSteno, D. (2006). Gratitude and prosocial behavior: Helping when it costs you. Psychological Science, I 7(4), 319-325.

Batson, C. D., \& Shaw, L. L. (199I). Evidence for altruism: Toward a pluralism of prosocial motives. Psychological Inquiry, 2(2), 107-I22.

Blanton, L., \& Pugach, M. (2007). Collaborative programs in general and special teacher education. Washington, DC: Council of Chief State School Officers.

Blau, P. M. (1964). Social exchange theory. Retrieved September, 3(2007), 62-79. 
Brown, J. L., Jones, S. M., LaRusso, M. D., \& Aber, L. (2010). Improving classroom quality: Teacher influences and experimental impacts of the 4R's program. Journal of Educational Psychology, 102, 153-167.

Brown, C. S. (2019). The importance, and the challenges, to ensuring an inclusive school climate. Educational Psychologist, 54(4), 322-330.

DOI: $10.1080 / 00461520.2019 .1655646$.

Buyse, E., Verschueren, K., Verachtert, P., \& Van Damme, J. (2009). Predicting school adjustment in early elementary school: Impact of teacher-child relationship quality and relational classroom climate. The Elementary School Journal, II0, |19-141.

Caprara, G. V., Steca, P., Zelli, A., \& Capanna, C. (2005). A new scale for measuring adults' prosocialness. European Journal of Psychological Assessment, 2I(2), 77-89. DOI: 10.1027/I0I5-5759.21.2.77.

Carlson, M., Charlin, V., \& Miller, N. (1988). Positive mood and helping behavior: A test of six hypotheses. Journal of Personality and Social Psychology, 55(2), 2II-229.

Chan, D., W. (2013). Subjective well-being of Hong Kong Chinese teachers: The contribution of gratitude, forgiveness, and the orientations to happiness. Teaching and Teacher Education, 32, 22-30.

Clark, M. S., Oullette, R., Powell, M. C., \& Milberg, S. (1987). Recipient's mood, relationship type, and helping. Journal of Personality and Social Psychology, 53(I), 94-IIO.

Clark, H. B., Northrop, J. T., \& Barkshire, C. T. (1988). The effects of contingent thank-you notes on case managers' visiting residential clients. Education and Treatment of Children, 7, 45-5I.

Eisenberg, N., Guthrie, I. K., Cumberland, A., Murphy, B. C., Shepard, S. A., Zhou, Q., \& Carlo, G. (2002). Prosocial development in early adulthood: a longitudinal study. Journal of Personality and Social Psychology, 82(6), 993-1006. DOI: 10.1037/0022-35|4.82.6.993.

Emmons, R.A., \& McCullough, M.E. (2004). The psychology of gratitude. New York: Oxford University Press.

Emmons, R. A., \& McCullough, M. E. (2003). Counting blessings versus burdens: an experimental investigation of gratitude and subjective well-being in daily life. Journal of Personality and Social Psychology, 84, 377-389.

Emmons, R. A., \& Crumpler, C. A. (2000). Gratitude as a human strength: Appraising the evidence. Journal of Social and Clinical Psychology, 19(I), 56-69. 
Forlin, C. (Ed.). (2010). Teacher education for inclusion: Changing paradigms and innovative approaches. Routledge.

Fredrickson, B. L. (2004). Gratitude, like other positive emotions, broadens and builds. The Psychology of Gratitude, 145, 166-17I. Oxford: Oxford University Press

Garg, N. \& Gera, S. (2019). Gratitude and leadership in higher education institutions: Exploring the mediating role of social intelligence among teachers. Journal of Applied Research in Higher Education, I2(5), 9I5-926. DOI: I0.I I08/JARHE-09-20 I9-024 I

Goldman, M., Seever, M., \& Seever, M. (1982). Social labeling and the foot-in-the-door effect. The Journal of Social Psychology, II 7(I), 19-23.

Grant, A. M., \& Gino, F. (2010). A little thanks goes a long way: Explaining why gratitude expressions motivate prosocial behavior. Journal of Personality and Social Psychology, 98(6), 946 -955. DOI: 10.1037/a0017935

Grant, A.M., Dutton, J.E., \& Rosso, B.D. (2008). Giving commitment: Employee support programs and the prosocial sense making process. Academy of Management Journal, 5I, 898-9/8. https://doi.org//0.5465/amj.2008.34789652

Hegtvedt, K. A. (1990). The effects of relationship structure on emotional responses to inequity. Social Psychology Quarterly, 53, 214-228.

Hodkinson, A. J. (2005). Conceptions and misconceptions of inclusive education: A critical examination of final year teacher trainees' knowledge and understanding of inclusion. International Journal of Research in Education, 73, I5-29.

Howells, K. (2014). An exploration of the role of gratitude in enhancing teacher-student relationships. Teaching and Teacher Education, 42, 58-67.

Isen, A. M., \& Levin, P. F. (1972). Effect of feeling good on helping: cookies and kindness. Journal of Personality and Social Psychology, 2 I (3), 384-388.

Jones, P. (2006). They are not like us and neither should they be: issues of teacher identity for teachers of pupils with profound and multiple learning difficulties. Disability \& Society, 19(2), 159-169.

Kaplan, I., Lewis, I., Mumba, P. (2007). Picturing global educational inclusion? Looking and thinking across students' photographs from the UK, Zambia and Indonesia. Journal of Research in Special Educational Needs, 7(I),23-35. DOI: 10.1III/j.147I3802.2007.00078.x. 
Lambe, J., \& Bones, R. (2006). Student teachers' perceptions about inclusive classroom teaching in Northern Ireland prior to teaching practice experience. European Journal of Special Needs Education, 22(2), 167-186.

Lambert, N. M., Fincham, F. D., Braithwaite, S. R., Graham, S. M., \& Beach, S. R. (2009). Can prayer increase gratitude?.Psychology of Religion and Spirituality, I(3), I39-I49. DOI: $10.1037 / \mathrm{a} 001673$ |

Lane, J., \& Anderson, N. H. (1976). Integration of intention and outcome in moral judgment. Memory \& Cognition, 4(I), I-5.

Majoko, T. (2019). Teacher key competencies for inclusive education: Tapping pragmatic realities of Zimbabwean special needs education teachers. SAGE Open, 9(I), 2158244018823455.

Maldonado-Carreño, C., \& Votruba-Drzal, E. (20II). Teacher-child relationships and the development of academic and behavioral skills during elementary school: A withinand between-child analysis. Child Development, 82, 60I-6I6.

McCullough, M. E., Kilpatrick, S. D., Emmons, R. A., \& Larson, D. B. (200I). Is gratitude a moral affect?. Psychological Bulletin, I27(2), 249-266

McCullough, M., Emmons, R., \& Tsang, J. (2002). The grateful disposition: A conceptual and empirical topography. Journal of Personality and Social Psychology, 82, II2-127. Retrieved from http://dx.doi.org//0.1037/0022-35/4.82.1.1 I2

McCullough, M. E., Tsang, J. A., \& Emmons, R. A. (2004). Gratitude in intermediate affective terrain: Links of grateful moods to individual differences and daily emotional experience. Journal of Personality and Social Psychology, 86, 295-309.

Minister of National Education Regulation No. 70. (2009). Inclusive education in Indonesia. -

Rind, B., \& Bordia, P. (1995). Effect of Server's "Thank You" and Personalization on Restaurant Tipping I. Journal of Applied Social Psychology, 25(9), 745-75I. DOI: https://doi.org/10.1III/j.1559-1816.1995.tb01772.x

Robbins, S.P. (2002).Organizational behavior. New Delhi: Prentice Hall.

Robertson, K., Chamberlain, B., \& Kasari, C. (2003). General education teachers' relationships with included students with autism. Journal of Autism and Developmental Disorders, 33, 123-130. 
Robinson, D. (2017). Effective inclusive teacher education for special educational needs and disabilities: Some more thoughts on the way forward. Teaching and Teacher Education 6 I (2017) I64-I78. DOI: I0.1016/j.tate.2016.09.007.

Safran, J. S., \& Safran, S. P. (200I). School-based consultation for Asperger syndrome. Journal of Educational and Psychological Consultation, 12, 385-395.

Sandage, S. J., Hill, P. C., \& Vaubel, D. C. (20II). Generativity, relational spirituality, gratitude, and mental health: Relationships and pathways. International Journal for the Psychology of Religion, 2I, I-16.

Schroeder, D. A., Penner, L. A., Dovidio, J. F., \& Piliavin, J. A. (1995). The psychology of helping and altruism: Problems and puzzles. McGraw-Hill.

Slee, R. (200I). Inclusion in practice: Does practice make perfect? Educational Review, 53(2), II3-123.

Sunardi, Yusuf, M., Gunarhadi, , Priyono, , \& Yeager, J. L. (20II). Theimplementation of inclusive education for students with special needs in Indonesia. Excellence in Higher Education, 2(I), I-I0. DOI: http://doi.org/I0.5 I95/EHE.20II.27.

Tesser, A., Gatewood, R., \& Driver, M. (1968). Some determinants of gratitude. Journal of Personality and Social Psychology, 9(3), 233-236. DOI: 10.1037/h0025905.

Tom, K. M. (20I2). Measurement of teacher's social-emotional competence: development of the social-emotional competence teacher rating scale. (Doctoral dissertation) University of Oregon: Department of Special Education and Clinical Sciences.

Trivers, R. L. (197I). The evolution of reciprocal altruism. The Quarterly Review of Biology, 46(I), 35-57.

Tsang, J. A. (2006). Brief report gratitude and prosocial behavior: An experimental test of gratitude. Cognition and Emotion, 20(I), I38-148.

Tsang, J. A., Schulwitz, A., \& Carlisle, R. D. (20I2). An experimental test of the relationship between religion and gratitude. Psychology of Religion and Spirituality, 4(I), 40-55. DOI: 10.1037/a0025632.

Tsang, J. A., \& Martin, S. R. (2019). Four experiments on the relational dynamics and prosocial consequences of gratitude. The Journal of Positive Psychology, 14(2), I88205. DOI:10.1080/17439760.2017.1388435. 
Yell, M. L., Katsiyannis, A., Drasgow, E., \& Herbst, M. (2003). Developing legally correct and educationally appropriate programs for students with autism spectrum disorders. Focus on Autism and Other Developmental Disabilities, |8, |82-191. 